\title{
@®ङ ENKVIST, Inger. Educação: Guia para perplexos. Campinas-SP: Kirion, 2019. 142 p.
}

Resenha do livro: ENKVIST, Inger. Educação: Guia para perplexos. Campinas-SP: Kirion, 2019. 142 p.

José Normando Gonçalves Meira*

Inger Enkvist é professora de literatura espanhola na Universidade de Lund, na Suécia e estudiosa das ideias pedagógicas e práticas educativas, com vasta publicação de ensaios e livros sobre o tema, analisando-o em suas aplicações em diferentes contextos. É conhecida por sua crítica às abordagens pedagógicas que se tornaram hegemônicas a partir da metade do século XX, as quais ela sintetiza sob o título de " nova pedagogia", contrastando-as com os pressupostos teóricos e práticas da chamada "pedagogia tradicional". Na obra em análise, a autora procura esclarecer o conceito de "pedagogia tradicional" ou "educação tradicional" que, segundo ela, normalmente é apresentado de forma superficial, pejorativa e até caricatural. Remete-se à filosofia clássica para apresentar os fundamentos dessa tradição que já vem sendo negada desde que a educação passou a ser pensada dos pontos de vistas utilitarista e igualitarista, desde o século XIX, culminando na hegemonia de tais pressupostos em meados do século XX. Aponta a crise atual como, em grande parte, consequência dessa "nova" percepção. Nessa abordagem introdutória, propõe aos educadores o aprofundar-se no conhecimento dos conceitos e princípios educação

\footnotetext{
* Doutor em Educação pela Pontifícia Universidade Católica de São Paulo (PUC/SP). Professor na Universidade Estadual de Montes Claros (UNIMONTES). E-mail: meirajng@ gmail.com. ORCID: https://orcid.org/0000-0003-1105-4322 CV: http://lattes.cnpq.br/9386435620693811
} 
tradicional, refletindo sobre as suas implicações práticas e os resultados obtidos por países que ainda os adotam. Realiza também uma avaliação dos pressupostos da "nova pedagogia" e as suas possíveis relações não apenas com os resultados da educação escolar, mas implicações sociais mais amplas. Aborda as diversas aplicações do conceito de educação e espaços onde ela é realizada, delimitando o seu enfoque a educação escolar e as suas relações. Discute os fundamentos epistemológicos da educação, o papel do professor, sua formação e postura profissional, as disciplinas escolares, seus objetivos e métodos de ensino e aprendizagem, bem como os papéis da instituição escolar, do aluno e a imprescindível colaboração da família. Aborda ainda a educação como política de Estado, refletindo sobre avaliações dos sistemas de ensino em diferentes contextos.

Enkvist (2019) discute inicialmente o conceito de educação em suas diversas aplicações e nos vários espaços de sua realização, enfatizando aquela que é produzida no âmbito da família e da escola. Nesse aspecto, apesar das diferenças de objetivos e fundamentação teórica, a abordagem lembra Brandão (2001), apontando quão amplo é este conceito e a diversidade de possibilidades de suas aplicações, sendo a educação escolar apenas uma delas. Mesmo sendo o objetivo da autora tratar especificamente da educação escolar, reconhece a necessidade de articular a sua abordagem aos outros aspectos e instituições relacionadas. Para ela, "a educação de um jovem é um projeto de colaboração entre o próprio jovem, a família, a escola e a sociedade" (p.71).

Apresenta inicialmente a questão epistemológica. Entende que para aprofundar-se nessa compreensão é imprescindível o debate sobre conceitos centrais como conhecimento, ciência, realidade e verdade. Problematiza o relativismo atual que, segundo ela, acaba culminando em niilismo, afetando fundamentalmente as práticas pedagógicas e a formação dos estudantes. Se a verdade não existe, não há conhecimento a ser transmitido. Nessa perspectiva, o aluno é que deve organizar a sua própria agenda de aprendizagem e a aquisição dos saberes deixa de ser uma questão de mérito (p.13,14). A autora considera óbvio que não se deve negar a pertinência do estímulo à criatividade dos alunos e de que a escola não deve ser autoritária, 
mas considera prejudicial a negação da verdade e da realidade, por "desestabilizar a educação" e propõe consideração cuidadosa sobre as contradições e sutilezas desse pressuposto. Recorre à antiguidade clássica para reforçar o seu argumento:

Desde Sócrates, saber em que consiste a verdade é a condição para agir de maneira virtuosa, porque o mundo do verdadeiro conhecimento e do ato virtuoso é apenas um ou, dito em outras palavras, a epistemologia e a ética são duas facetas da mesma coisa (ENKVIST, 2019, p. 16).

Essa negação da realidade, de uma moral objetiva, aprofundando-se no relativismo, mina as bases da educação que deveria levar "o jovem a ser capaz de escolher o bem em sua vida" (p. 30). Deixando de buscar a verdade, os adeptos dessa nova mentalidade, ancorando valores sobre pressupostos ideológicos, mereceriam crítica análoga à que Platão fazia aos sofistas (p. 39), podendo alguns pedagogos adeptos dessa corrente epistemológica ser considerados "sofistas modernos" (p.40). Mesmo considerando as limitações humanas para se ter acesso à verdade em sua plenitude, a educação tradicional, fundamentada no pensamento clássico e na cosmovisão cristã, reconhece a existência da verdade e a necessidade do exercício contínuo para buscá-la. Nessa perspectiva, o verdadeiro, o bom e o belo compõem a tríade do viver virtuoso.

No que se refere à profissão docente a autora dedica especial atenção por considerar necessário a recuperação da consciência da importância desse profissional no processo educativo. Ressalta a importância de uma formação longa e contínua a exemplo de outras profissões tais como a do advogado e a do médico. Profissões que exigem saber especializado, domínio de teorias, terminologia específica e prática adequada. Considerando que cada área de atuação tem a sua ética, esta deve ter ênfase especial na formação do professor que além de desenvolver a sua competência, deve ser capaz de autoavaliar-se. Ressalta as habilidades exigidas do profissional docente que, além de dominar os conhecimentos específicos, precisa ser criativo para ser capaz de adaptar o ensino desses 
conteúdos às situações específicas. Uma profissão que exige especial, energia física e psíquica, maturidade, senso de responsabilidade e até senso de humor. Provoca reflexões referentes às condições do trabalho docente. As lacunas apontadas são até surpreendentes, considerando que a Europa é a principal referência de realidade da autora. Menciona a importância da estabilidade em uma determinada instituição escolar, onde poderá contribuir mais efetivamente não apenas com os seus alunos e com a comunidade, como também com os colegas, criando vínculos importantes para a contínua formação e troca de experiências. Observa que " as pessoas alheias ao mundo da educação talvez não percebam a importância de um professorado estável para uma escola" (p. 73). Ainda sobre as condições do trabalho docente, afirma que:

Os professores precisam ter uma vida intelectual própria para alimentar a sua mente. Precisam de tempo para ler livros, ir a concertos e viajar. Para estimular outros é preciso armazenar ideias e conhecimentos, e, além disso, renovar-se continuamente. A palavra "professor" deveria a imagem de alguém aficionado pelos livros, alguém que acorre avidamente quando se organiza uma conferência com um intelectual famoso da capital ou se apresenta um espetáculo teatral. Deveríamos encontrar o professor frequentemente na livraria local e na biblioteca pública. Quando o professor "enche o estoque" dessa maneira, pode falar em aula dos temas culturais com entusiasmo, e seu vocabulário se enriquece (EKVIST, 2019, p. 73)

Naturalmente a busca por tal condição é responsabilidade do professor individualmente, mas depende também das condições que lhes são proporcionadas. A autora menciona também os aspectos físicos e psíquicos relacionados à saúde do professor que devem ser levados em consideração para que ele desempenhe o seu papel que, nessa perspectiva é central no processo educativo.

As abordagens atuais, influenciadas pelas tendências igualitaristas, na perspectiva da autora, contribuem para a desvalorização da profissão docente: "Diluiu-se a figura do professor, como consequência da nova 
pedagogia" (p. 78). A justa preocupação em que o professor não seja um autoritário leva ao outro extremo, exigindo que seja meramente um carismático, mas destituído da autoridade e, consequentemente, da responsabilidade de assumir a efetiva direção do processo de produção do conhecimento. Afinal, todos são iguais no processo, todos ensinam e aprendem, sendo o professor apenas um "facilitador". Essa erosão das hierarquias provocadas pelas reivindicações democráticas, é objeto de análise de Minogue (2019) que mesmo exaltando o sistema democrático como desejável, aponta distorções possíveis. Uma delas é a rejeição da autoridade, em nome da igualdade, promovida por movimentos da década de 1960, tendo implicações nos relacionamentos familiares e nas práticas escolares, na relação professor-aluno, onde a autoridade do professor é desconstruída. A disciplina, substituída pela negociação, para que todas as frustrações sejam eliminadas, inclusive a reprovação. A premiação deve ser para todos, independentemente dos resultados obtidos.

A autoridade do professor, nos moldes tradicionais, segundo Enkvist (2019), é constituída mediante o domínio dos conhecimentos norteadores das ações dos alunos que devem obedecer as suas instruções. Além do conhecimento dos conteúdos, o professor deve ser o portador de valores éticos que sirvam de modelo para os alunos, principalmente do nível "primário ao ensino médio" (p. 76.77). Nesse "contrato social” os alunos estarão aprendendo a trabalhar, segundo as normas, tal como as que terão que enfrentar em diferentes situações quando forem adultos. O professor, com os seus conhecimentos, experiência e caráter, estará assim, preparandoo para este objetivo. A tendência atual, entretanto, desconsiderando a autoridade do professor, é permissiva com os alunos desinteressados e até com os que dificultam a aprendizagem dos outros, favorecendo a indisciplina e, neste caso, acaba cometendo injustiça para com os interessados nos estudos que têm o seu progresso prejudicado.

Nessa perspectiva tradicional, o professor é o responsável por organizar e conduzir a experiência da aprendizagem. O objetivo é a formação intelectual, articulando-a à formação do caráter. Convictos da “importância da beleza, da verdade e da bondade" (p. 80), procuram 
transmitir esses valores de forma integrada com a matéria que ensinam. Além dos conhecimentos, portanto, inclui-se a formação do caráter que fará a diferença nas ações do indivíduo na sociedade. Essa perspectiva alinha-se ao que considera Reed (2019, p. 7,8):

[...] o caráter faz toda a diferença no mundo. Você é responsável por seu próprio caráter e pode exercer influência considerável sobre o caráter dos outros pelo seu exemplo [...] Se valoriza a liberdade, precisa entender que o caráter é um ingrediente indispensável - uma precondição necessária - para uma sociedade livre [...] $\mathrm{O}$ caráter vem em primeiro lugar e torna a liberdade possível, e um dos chamados mais nobres de um adulto responsável em uma sociedade livre é ser um empreendedor honesto que gera valor, emprega pessoas e resolve problemas

Para a formação do caráter, as facilidades propostas pela "nova pedagogia" são também empecilho. No entendimento da autora: "Se a escola e a família não exigem esforços dos jovens, deixam-nos mal preparados para enfrentar as dificuldades e frustrações que encontrarão durante a vida" (p.104). As dificuldades do trabalho e as frustrações dos estudantes, bem orientados pelos professores, podem ser estímulos para superações. Aprender a respeitar prazos, normas pré-estabelecidas para apresentação dos trabalhos, assumindo as consequências quando não são cumpridas, podem ser fatores importantes no preparo dos estudantes para a vida.

Sobre as motivações para a escolha da profissão docente, ressalta a consciência da sua relevância e da disposição interior para servir à sociedade. A realidade caótica dos sistemas de ensino e das instituições, escolares, entretanto tem sido elemento de desmotivação. Comenta:

$\mathrm{O}$ ambiente anti-intelectual instaurado em muitos colégios, afasta os jovens que poderiam ter escolhido essa profissão. Desencantados com o que veem, preferem buscar outras saídas profissionais antes de se responsabilizarem por uma política educacional que 
não funciona [...] os responsáveis políticos e administrativos falam sem parar de profissionalismo, qualificação, certificados e renovação, e por isso é difícil para pessoas que estão fora do mundo entender o que aconteceu (ENKVIST, 2019, p. 78)

Ao discutir as disciplinas escolares e o seu processo de ensino e aprendizagem, a autora aponta a necessidade de se conhecer a história dessas disciplinas, como elas se constituíram, qual a sua relevância social e os problemas específicos de cada área, bem como as suas conexões com áreas afins e mesmo com outros campos científicos. Os conhecimentos não devem ser produzidos de forma isolada. Também neste aspecto, enfatiza a importância do professor e os seus conhecimentos prévios para a delimitação de temas e para a introdução dos estudantes "em territórios até então desconhecidos por eles" (p. 81). Também neste aspecto, considera inadequadas as tendências pedagógicas que transferem para o aluno a responsabilidade de "construir" o seu próprio conhecimento. Entende que, mesmo que essa transferência de responsabilidade ocorra de forma parcial, há uma desestabilização do processo, colocando o estudante diante de problemas que ele ainda não está apto para resolver. Os alunos podem e devem ser envolvidos no processo de desenvolvimento dos conteúdos específicos de cada disciplina, mas sob uma direção segura dos professores. Menciona os recursos tecnológicos como aliados das práticas educativas, mas que devem ser utilizados de forma sistemática, orientada, considerando, por exemplo, as vantagens das leituras realizadas nos livros em relação aos sites e aos formatos eletrônicos em geral, principalmente no que diz respeito à concentração do leitor. Reflete também sobre questões relacionadas ao estresse tecnológico. O cuidado para não tornar prejudicial o que é útil e construtivo. Critica ainda a predominância do caráter utilitarista dos currículos escolares, privilegiando matérias que tenham vínculo direto com a utilidade econômica e diminuindo as horas das disciplinas de formação humana, tais como literatura e história. Problematiza o próprio ensino dessas disciplinas, na perspectiva do "pensamento crítico": 
Desde à queda do muro de Berlin, os neomarxistas já não apresentam o seu pensamento como sendo marxismo, mas como pensamento crítico [...] Nos departamentos universitários de ciências sociais, assim como nos meios de comunicação - e certamente nas escolas - constata-se a influência de intelectuais críticos, no sentido de negativos, contra a própria sociedade [...] paradoxalmente ,os grupos críticos de sua própria sociedade se apresentam como campeões dos direitos humanos, elaborados precisamente pelas sociedades ocidentais [...] Considera-se um exemplo de espírito crítico não admirar nada nem ninguém e, em particular, curiosamente, ninguém ligado à própria cultura. Talvez haja uma relação entre o desprezo pelos grandes nomes e o desprezo geral pela excelência (INKVIST, 2019, p.84,85)

Nessa análise, lembra também as observações de Minogue (2019) que ao tratar da cultura ocidental, suas origens e desdobramentos, apresenta, por um lado, interpretações que exaltam as peculiaridades de uma civilização fundamentada na liberdade, democracia, geradora de riquezas e conhecimentos, além da influência nas artes e na política de tal forma que tornou-se referência para o mundo inteiro e, por outro, a tendência de rejeição e revolta, surgida no próprio ocidente. Os críticos, segundo ele, ignoram as realizações da modernidade ocidental e enfatizam as suas imperfeições e a denominam, pejorativamente, "capitalismo".

Quanto à participação dos alunos, a autora entende que, a exemplo de outras áreas da vida em que se pretenda adquirir certas habilidades, é necessário que haja muito esforço, disciplina, perseverança e dedicação de tempo. Cita como exemplo as habilidades nas práticas esportivas e na execução de instrumentos musicais. Essa dedicação certamente requererá renúncias que trarão recompensas futuras. Questiona a teoria predominante de que os maus resultados escolares são consequência dos problemas socioeconômicos, sendo a educação escolar apenas "reprodutora das desigualdades sociais". Sem desconsiderar a importância desse fator, adverte para o prejuízo de se negar a responsabilidade individual do aluno e do apoio da sua família no esforço requerido para a sua formação, 
atribuindo-a ao "determinismo socioeconômico". Argumenta, apresentando dados de avaliações internacionais que apontam o sucesso de comunidades que, apesar das desfavoráveis condições socioeconômicas, apresentaram resultados superiores, como, cita como exemplo, estudo sobre o desempenho de meninas filhas de imigrantes em países europeus. Situações em que o esforço do aluno, com o apoio da família revelou-se fator fundamental para os resultados obtidos. Conclui: "De nenhuma maneira se chega a ter uma boa educação escolhendo a tarefa e o nível de esforço conforme a inspiração do momento" (p. 103).

A colaboração entre família e escola é apresentada como primordial para a formação moral, intelectual e prática. A família é a "minissociedade" onde a criança aprende que não é o centro do mundo e que deve estar sujeita às normas e aos limites da convivência no grupo. Além de ser modelo moral, de honra, cumprimento dos deveres e gentileza nos relacionamentos, os pais devem também ser exemplo dos filhos na busca de conhecimentos. Independentemente do nível de escolaridade dos pais, esse esforço para respaldar a mensagem passada pela escola, favorecerá o engajamento das crianças, criando nelas o gosto e a consciência da necessidade de empenho nos estudos. Ao final da obra a autora discute, de forma sucinta, também a importância da sensibilidade da família e da escola na constatação de dificuldades de aprendizagem decorrentes de problemas que requerem ajuda especializada, tais como dislexia, déficit de atenção, hiperatividade, ansiedade e outros, apontando possibilidades de tratamento.

Comenta resultados do Programa Internacional de Avaliação de Alunos - PISA, apontando os países que tem ocupado as melhores colocações, são países que mantiveram os seus sistemas de ensino fundamentado na pedagogia tradicional. Estes países não se rendem ao "determinismo socioeconômico", mas "mantêm o seu foco de atenção no aprendizado através do esforço por parte do aluno, e da parte do professor, no conhecimento e na capacidade de ensinar" (p. 27). Ressalta que estes países, além de conseguirem melhores resultados educacionais, conseguem também mais igualdade social (p. 27). Cita como exemplo a Finlândia, Coréia do Sul, Hong Kong, Singapura e outros. Considerando a 
possibilidade de identificar características similares da chamada "pedagogia tradicional” em diversas culturas, afirma: "Os países asiáticos, decididos a suplantar os países ocidentais, mantiveram a pedagogia tradicional e agora são os primeiros nas comparações internacionais" (p. 94).

Enkvist (2019) oferece a possibilidade de análise da pedagogia tradicional, ou de uma versão dessa corrente teórica, a partir das afirmações de quem a representa. Contribui para uma análise comparativa das apresentações da referida teoria por parte dos seus críticos. $\mathrm{O}$ seu estudo enriquece o debate acadêmico, aberto à pluralidade de ideias, submetendoas às investigações racionais, evitando elaborações apressadas e caricaturais. A obra é relevante por suscitar reflexões para além da área específica da educação, aplicando-se às ciências sociais em geral. A leitura é recomendada para alimentar reflexões no meio acadêmico, nos cursos de formação inicial e continuada de professores.

\section{Referências}

BRANDÃO, Carlos Rodrigues. O Que é Educação. São Paulo: Brasiliense, 2001

MINOGUE, Kenneth. A Mente Servil: como a democracia solapa a moral. São Paulo, É Realizações, 2019

REED, Lawrence W. Como se Preparar Para Uma Economia Liberal: Princípios e práticas para destacar-se no novo cenário. São Paulo: Faro Editorial, 2019

Data de registro: 01/10/2020

Data de aceite: 22/09/2021 